\title{
Judging Theistic Arguments
}

In a very interesting recent article ("Who Are The Best Judges Of Theistic Arguments?" Sophia 35, 2, 1996, pp.1-12), Mark Nelson argues that the best judges of arguments for the existence of God are theists whose belief in God is properly basic. I propose to take up two questions here. First, does Nelson's argument succeed in establishing his conclusion? Second, if Nelson's argument were successful, what significance would it be appropriate to attribute to his conclusion? I shall begin with a brief rehearsal of his argument, and a discussion of some questions about the proper formulation of his argument which immediately arise.

Nelson's case proceeds by analogy with the law. The best judges in legal cases are those who are able, honest, and without vested interest in the case at hand. By 'parity of reasoning', the best judges in philosophical cases will be those who are able, honest, and without vested interest in the case at hand. But the only people who are suitably disinterested in the convincingness of arguments for the existence of God are theists who take their belief in God to be properly basic (i.e. theists who believe that God exists, but who do not take the rationality of their belief to depend on the convincingness of any 
theistic argument). Hence the best judges of arguments for the existence of God are able, honest theists who take their belief in God to be properly basic.

Following Mavrodes, Nelson says that an argument is convincing just in case it is valid, possesses premises which are known to be true, and possesses premises which are capable of being known independently of knowledge of the conclusion of the argument. On this account, if an argument is convincing it is sound, but there may be many arguments which are sound but not convincing. (In particular, any valid argument from true but not known premises is sound but not convincing.) Initially, Nelson supposed that his judges should simply be judging the soundness of arguments for the existence of God. However, consideration of arguments such as the following:

(1) If $2+2=4$, then God exists

(2) $2+2=4$

(3) (Therefore) God exists

shows immediately that no reasonable theist can be indifferent to the soundness of all theistic arguments. Unfortunately, this very same example also shows that no reasonable theist can be indifferent to the convincingness of all theistic arguments. First, the argument is valid. (We are free to stipulate that the logic is classical.) Second, reasonable theists seem bound to concede that the premises are known to be true. (Apart from anything else, it seems clear that an omniscient God is bound to know them!) And, third, if God exists, then the premises are capable of being known independently of knowledge 
of the conclusion of the argument, since one could come to know (1) via the testimony of a reliable informant, and then use (2) to infer (3). (Theists can hardly deny that it is possible to acquire knowledge via testimony; typically, a great deal of religious knowledge is supposed to be acquired in this way.) So it appears that there are good reasons for thinking that no reasonable theist can be indifferent to the convincingness of our sample argument.

Supposing that this objection is granted, one might think that the proper response is just to say that Mavrodes' notion of convincingness is not the notion which Nelson needs for his argument. In order to investigate this suggestion, we need to ask ourselves exactly what it is that Nelson's judges are supposed to be doing.

For the moment, let us suppose that, whatever else we shall require of the notion of convincingness, we shall at least require that only sound arguments can be convincing. A natural first thought — apparently consistent with everything that Nelson says — is that the task of the judges is to issue verdicts on the convincingness of arguments (i.e. to say 'convincing' or 'not convincing' for each theistic argument in turn). Moreover, it seems natural to think that the best judges will be the ones who get their verdicts right-i.e. if there are judges who are $100 \%$ accurate, then they are the best judges (and, indeed, the 
best possible judges); if there is no-one who is $100 \%$ accurate, then the best judges are those who get the highest percentage of correct verdicts; etc.

But now suppose that there is someone who knows that there is no God, and who uses just this knowledge in order to judge all theistic arguments unconvincing. Such a person cannot be bettered as a judge of the convincingness of theistic arguments, for they know that theistic arguments are one and all unconvincing. Of course, if the main task of the judges is to issue more detailed verdicts_-"unconvincing because invalid", "unconvincing because premise is false", ...-then we shall require other abilities in our ideal judge, but it will nonetheless be true (in the envisaged circumstances) that knowing that there is no God is bound to better qualify one as a judge. (There seems to be an important disanology here with the case of law—a legal judge might know that a defendent is guilty, but on grounds which are inadmissible at law. In that case, the judge might be obliged to issue a verdict of 'not guilty'. But one who knows that there is no God cannot be obliged to say that a theistic argument is sound.)

Perhaps one might object that one ought not to place too much weight on the possibility that one might know that there is no God. No matter-for the purposes of the preceding argument, all we really need consider is the case of someone who (reasonably?) believes that there is no God in circumstances in which there is no God, and who is prepared to use this belief in judging the convincingness of theistic arguments. Given that alethic considerations are an important factor in the assessment of the convincingness of 
arguments, it remains the case that this kind of person cannot be bettered as a judge of the convincingness of theistic arguments, since their judgments will be universally accurate.

One might be tempted to think that the above argument improperly ignores the modal component in the notion of a good judge: to be a good judge is not just to make judgments which happen to be correct, but to be modally robust in making judgments which are correct (i.e. roughly, to also make correct judgments in nearby worlds). This sounds right: a good judge of the truth of the proposition that $\mathrm{p}$ is someone who is such that their judgments of the truth of the proposition that $\mathrm{p}$ track the truth of the proposition that $\mathrm{p}$. But then, so long as we hold onto the insistence on an alethic dimension in the assessment of the convincingness of arguments for the conclusion that $\mathrm{p}$, it seems clear that the best possible judges of the convincingness of arguments for the conclusion that $p$ will be those whose judgments track the truth of the proposition that $\mathrm{p}$. Thus, in the case at hand, the best possible judges of the convincingness of theistic arguments will be those who beliefs track the truth concerning the proposition that God exists. If there is no God, then it certainly will not be the case that theists who take their belief in God to be properly basic are the best judges of the convincingness of arguments for the existence of God-and even if there is a God, it may be that theists who take their belief in God to be properly basic are not amongst the best judges, because their beliefs do not track the truth in nearby worlds. Of course, if God is necessarily existent and the proper basicality of their beliefs is modally robust, then theists who take their belief in God to be properly basic can be amongst the best judges - but even then, it seems clear that there will be others who are also amongst the best judges. 
Nothing in what I have said really turns on the initial assumption that the judges are merely to issue a verdict about theistic arguments ("convincing" or "not convincing" as the case may be). Even if the judges are required to do much more- e.g. to document all of the logical failings of unconvincing arguments - it will still be the case that one of the qualities which any ideal judge of arguments for the proposition that $\mathrm{p}$ will have is the ability to track the truth of the proposition that $\mathrm{p}$. If there is an alethic dimension to the convincingness of arguments, then it seems clear that Nelson's argument is highly suspect - theists who take their belief in God to be properly basic will be among the best judges of the convincingess of theistic arguments only if certain much contested conditions obtain, and there is a wide range of conceivable circumstances in which they will not be amongst the best judges at all.

In view of the conclusion of the preceding section, perhaps it is now time to consider the possibility that there ought to be no alethic dimension to the notion of convincingness in which we are interested: when we assess theistic arguments for convincingness, we should ignore questions about the truth of the premises of those arguments, and instead focus exclusively on the ability of the argument to bring about certain kinds of revision of 
belief in reasonable persons. At least at first sight, it seems that, if an argument can bring some reasonable people with reasonable prior beliefs to believe in God, then that argument is convincing for those people. And, if an argument can bring all reasonable people with reasonable prior beliefs to believe in God, then that argument is convincing tout court. Can something like Nelson's conclusions be established using this kind of notion of convincingness? Are theists whose belief in God is properly basic the best judges of the convincingness (in the just specified sense) of arguments for the existence of God?

Consider the argument discussed in section 1 above. It is obvious that this is not a argument for the existence of God which is convincing tout court (in the sense now under consideration) - and it is equally plain that this argument could only be a convincing argument for a particular person in very special circumstances (and in a way in which any non-circular argument could be convincing for particular people in special circumstances). It doesn't require any particular expertise to be able to make this judgement - first-year philosophy students and non-philosophers are perfectly capable of making an accurate assessment of the convincingness of the argument (in the sense now under consideration). One 'sceptical' thought which now arises is that there may not be any theistic arguments whose convincingness cannot be assessed by any moderately intelligent person. Certainly, it is far from obvious that there is any sense of 'expertise' in which moderately intelligent persons ought to feel the need to defer to 'expert' opinion when confronted with questions about the convincingness of any arguments for the existence of God - and it is perfectly clear that there is no sense of 'expertise' in which 
moderately intelligent persons ought to feel the need to defer to 'expert' opinion when confronted with questions about the convincingness of some arguments for the existence of God (e.g. those which are obviously unconvincing). Moreover, a little reflection on the fact, that whether one ought to find an argument convincing depends upon your doxastic state (e.g. what else you believe, how firmly you believe it, and so on), seems to suggest that it is unlikely that there are any arguments for the existence of God which are convincing tout court - after all, one person's modus ponens is another person's modus tollens. (Perhaps it is also worth noting here that, if there are people who know that there is no God, then there can be no arguments for the existence of God which are convincing tout court - there is a route back from convincingness tout court to alethic considerations.) But once we focus on properties of arguments which are possessed only relative to target doxastic set-ups_-rather than on characteristics of arguments which can be recognised by alethically privileged individuals quite apart from their philosophical skills - the conclusion for which Nelson is arguing begins to sound quite implausible.

Even if we were to suppose that there is something like 'expertise' or 'judgment' which is required in the assessment of the convincingness of arguments for the existence of God, it isn't clear why we shouldn't simply insist that expert judgments just are the judgments of those who are best at assessing the convincingness of arguments, regardless of their beliefs about the conclusions of the arguments. True enough, one might have reasons for wanting certain arguments to fail to be convincing-one might want theistic arguments to fail to be convincing because one does not want to believe in God—-but all that matters is that one in fact makes judgements which are not influenced by one's 
desires. The best judges of the convincingness of theistic arguments may be those who most desire that the conclusions of those arguments are true, provided only that those desires do not illegitimately influence the process of assessment. (Again, there may be an important disanalogy with the law. If $I$ write a book which trenchantly defends theism, and succeed in my aim of winning the Templeton Prize, you may well be justifiably suspicious about the arguments which I have used. However, this kind of case aside, I suspect that most philosophers are much more concerned about the convincingness of their arguments than Nelson allows. (Who would not now be embarassed to have been a proponent of Malcolm's version of the ontological argument in Proslogion 3?) Indeed, the idea that philosophers actually are or would be illegitimately influenced by desire in their assessment of the convincingness of arguments seems to me to be rather implausible. (At least in part, this is because there is so little to gain, and so much (face) to lose: mistaken judgements about the convincingness of arguments are sources of embarrassment when they are highlighted in the philosophical literature. In the legal case, of course, there is far more to lose — but there is also much more to gain.) Moreover, there are also important institutional differences. In the case of philosophical argument, one is obliged to make up one's own mind, even if what one decides to do is to defer to a certain kind of expert opinion - it simply isn't the case that there are people who are delegated to form our opinions about philosophical questions. However, in the legal case, the judge is to produce a verdict which, in some sense, represents or constitutes the community judgment — and it is in part for this reason that we try to make sure that partisan desires play no part in judicial decisions. In the philosophical case, those of us who are not inclined to follow James' line on the will to believe may well feel that it is an 
individual failing to allow desires to infect our judgments about the worth of arguments - but we are not likely to follow Clifford in holding that those who do allow desire to infect judgement in this way somehow pollute the intellectual environment for everyone else.)

Nelson makes much of the suggestion that good judges will be indifferent to the content of their judgments. However, it seems to me that his argument at this point may rely on the choice of the less plausible of two different conceptions of 'best judge'. On the one hand, as I have already argued, it might be that the best judge is one who does not allow his desires to influence his judgment, no matter what the content or strength of those desires: that is a kind of ideal to which philosophers might aspire (though it is controversial whether they ought to do so). Given this conception of 'best judge', there is no reason why the best judges need to be indifferent to the truth or convincingness of the arguments which they consider (though they may perhaps need to be prepared to follow arguments where they lead). On the other hand, it might be that the best judge is the one who is deemed most likely not to allow her desires to influence her judgments when human frailties are factored in. Given this conception of 'best judge', there may be some reason to think that the best judges will be indifferent to the convincingness of the arguments which they consider - particularly since it is likely to be rather hard to get suitably independent evidence of (or objective judgments about) the desire-independence of one's judgments. (Perhaps there is something approaching a parallel to the legal case here: it is hard for judges to provide an objective assessment of the desire-independence of their judgments in some cases in which they have an interest; and it is hard for 
philosophers to provide an objective assessment of the desire-independence of their judgments of arguments in some cases in which they have an interest in the truth of the conclusion of those arguments. However, the appropriate conclusion to draw in the two cases seems to be rather different: in the legal case, we build in institutional provisions which try to make it the case that judges do not need to make the difficult assessments of desire-independence; in the philosophical case, we simply acknowledge that desireindependence is an ideal to which we aspire, and we criticise others when we note that they seem not to be living up to this ideal.)

Although there is much more to be said about the material discussed in this section, it seems to me that it is not unreasonable to conclude that it is unlikely that Nelson's argument will stand if we focus on a conception of convincingness which has no alethic dimension. If our question is one about the qualities of ideal judges, abstracting from any considerations about psychological limitations, then there is no reason at all to think that ideal judges of theistic arguments will be theists whose belief in God is properly basic. If, however, our question is one about who makes the best judgments given the cognitive limitations to which humans are invariably subject, then it is hard to see that there is any short and satisfactory answer - make up your own mind about the worth of theistic arguments and then you will have the best answer you are likely to get about who are the best judges of theistic arguments (namely, whoever agrees with the judgments that you have made!). 
Nelson insists that his argument is only meant to establish that theists whose belief in God is properly basic are the best judges of the convincingness of arguments for the existence of God; he allows that it might well be the case that atheists whose belief that God does not exist is properly basic are the best judges of the convincingness of arguments against the existence of God. Moreover, he might have gone on to saythough he does not - that for any of the many alternatives to the traditional conception of God, the best judges of the convincingness of arguments for the existence of any alternative God are those whose belief in the existence of that God is properly basic. So, for example, the best judges of arguments for the existence of an omnipotent, omniscient and perfectly evil God_-hereafter, God*_are those whose belief in God* is properly basic. Now, certainly, the case which Nelson makes for the claim, that theists whose belief in God is properly basic are the best judges of the convincingness of arguments for the existence of God, can be paralleled by a case for the claim, that the best judges of arguments for the existence God* are those whose belief in the existence God* is properly basic, which seems just as good as the case which Nelson makes for his favoured claim. And yet this seems to make a logical difficulty for the claim which Nelson defends - for, of course, the claim that God exists and the claim that God* exists are not logically independent. Judgments about the convincingness of arguments for God cannot be independent of judgments about the convincingness of arguments for God*- 
indeed, one of the standard criticisms of arguments for the existence of God is that they can all be paralleled by equally 'convincing' arguments for the existence of God*_-so it is hard to see how it could be the case that certain theists are the best judges of the convincingness of arguments for the existence of God, and certain theists* are the best judges of the convincingness of arguments for the existence of God*. (Of course, the same point could be made about judges of the convincingness of arguments against the existence of God. But there may be difficulties with the idea that belief in the nonexistence of God could be properly basic. At any rate, I have chosen to focus on questions about God* in order to side-step this difficulty.)

Perhaps we can make this argument a bit more explicit. Suppose that the proposition that $\mathrm{q}_{\mathrm{i}}$ entails the proposition that not $\mathrm{q}_{j}$ for all $\mathrm{j} \neq \mathrm{i}$. Then a convincing argument that $\mathrm{q}_{\mathrm{i}}$ will be a convincing argument that not $\mathrm{q}_{\mathrm{j}}$ for all $\mathrm{j} \neq \mathrm{i}$. Hence, if one is in a position to judge that there is a convincing argument that $\mathrm{q}_{\mathrm{i}}$, one is also in a position to judge that there is a convincing argument that not $\mathrm{q}_{\mathrm{j}}$ for all $\mathrm{j} \neq \mathrm{i}$ - and hence one is in a position to judge that there is no convincing argument that $\mathrm{q}_{\mathrm{j}}$, for all $\mathrm{j} \neq \mathrm{i}$. So, consider a judge who has a properly basic belief that $\mathrm{q}_{\mathrm{i}}$, and who (correctly) judges that a particular argument that $\mathrm{q}_{\mathrm{i}}$ is convincing. This judge must then be a best possible judge of the convincingness of arguments for the conclusions that $\mathrm{q}_{\mathrm{j}}$ and that not $\mathrm{q}_{\mathrm{j}}$, for all $\mathrm{j} \neq \mathrm{i}$ - and that contradicts the idea that the best possible judge of the convincingness of an argument for the conclusion that $\mathrm{r}$ is one whose belif that $\mathrm{r}$ is properly basic (at least for a suitable range of propositions which includes all of the propositions $\mathrm{q}_{\mathrm{k}}$ ). Of course, the contradiction can be avoided if there are no convincing arguments for any of the propositions that $\mathrm{q}_{\mathrm{i}}$ - but 
the claim that theists whose belief in God is properly basic are the best judges of theistic arguments provided that none of those arguments is convincing (nor judged by the judges in question to be convincing?) is rather less interesting than the claim with which Nelson began.

Even if the argument of the preceding section is incorrect, there is an aspect of the discussion which does stand: Nelson concedes that theists whose belief in God is properly basic are not the best judges of the convincingness of arguments against the existence of God (since they have a vested interest in the unconvincingness of these arguments). Moreover, he does hint that it might be that non-theists whose belief in the non-existence of God is properly basic are the best judges of the convincingness of arguments against the existence of God. The parity of the situation naturally suggests the following kind of question: What would be the consequences if Nelson's argument were correct? Suppose certain theists are the best judges of the convincingness of arguments for the existence of God—what then?

In advance, it seems that anything could happen. Perhaps the best judges of the convincingness of arguments against the existence of God will unanimously agree that a particular argument against the existence of God is convincing. Perhaps the best judges of 
the convincingness of arguments for the existence of God will unanimously agree that a particular argument for the existence of God is convincing. Of course, we won't get both of these outcomes if the judges are $100 \%$ reliable (though, in that case, any one of the relevant judges would serve as an oracle.)

If the best judges are not $100 \%$ reliable, then all kinds of possible scenarios open up. Suppose that for each of 10 arguments, $10 \%$ of the judges judge that it is the sole convincing argument for the existence of God. Should we who hear the verdict conclude that there is no convincing argument for the existence of God? (There are well-known limitative theorems on group decision-making which are likely to be relevant to the discussion at this point. However, I shall not take up these rather tangential considerations here.)

Moreover, there is clearly going to be an identification problem: even if it is true that the best possible judges are certain kinds of theists who take their belief in God to be properly basic, how are we know whether any of the best actual judges belong to this group? Clearly, there are all kinds of possible grounds for scepticism here: perhaps there really isn't anyone whose belief in God is properly basic; perhaps there are people whose belief in God is properly basic, but these are all people utterly without logical acumen; and so on. (Of course, the concept of 'properly basic belief' is not unproblematic. However, it would take us too far afield to consider the different ways in which the concept might be understood, not to mention the consequent questions about whether it 
is - or can be- the case that anything falls under the concept on those different understandings.)

And so on. The upshot seems to be that, even if Nelson's argument were good, the claim that it established would be a mere curiousity - i.e. not something which is in itself of any great theoretical importance. Perhaps there are further plausible assumptions which could be added to it in order to get some interesting consequences - but what those assumptions might be is at present something at which we can only guess.

\section{6}

In sum, I have argued: (i) that Nelson's argument fails no matter how the controversial notion of 'convincingness' is understood; (ii) that even if this were not so, Nelson's argument would be undermined by a kind of Many Gods objection; and (iii) that even if this were not so - and even if Nelson's argument were sound - it is far from clear that the conclusion of his argument has any interesting consequences for non-theists (or theists). Even if I am right about all this — and I must admit that some parts of my discussion are rather incomplete - it still seems to me that there is much of value in Nelson's paper: the questions to which his argument gives rise touch on many important issues in philosophy of religion, and his discussion casts new light on a not insignificant number of them. ${ }^{1}$ 


\section{NOTES}

${ }^{1}$ Thanks to an anonymous referee at Sophia for several very helpful comments which led to improvements in the final version of this paper. 